\title{
Fatty Acid Fingerprints of "Streptococcus milleri," Streptococcus mitis, and Related Species
}

\author{
D. B. DRUCKER AND S. M. LEE \\ Department of Bacteriology and Virology, University of Manchester, Manchester M13 9PT, Great Britain
}

\begin{abstract}
Whole-cell fatty acid methylester fingerprints of 83 streptococcal strains were determined by gas chromatography. The major cellular fatty acids were invariably tetradecanoic, hexadecanoic, octadecanoic, and octadecenoic acids. On the basis of "minor fatty acid" composition, it was possible to distinguish between three types of streptococci of uncertain taxonomic status, collectively referred to in the literature as "Streptococcus milleri," and two groups of serovars of Streptococcus mutans. Streptococcus mitis proved fairly heterogeneous, as expected. Streptococcus faecalis, Streptococcus pyogenes, Streptococcus salivarius, and Streptococcus sanguis had qualitatively distinct profiles.
\end{abstract}

Gas-liquid chromatographic chemotaxonomy (9) is now an established technique in microbiology. The application of chemical fingerprints to microbial classification has been pioneered by Abel et al. (1), who examined cellular fatty acids, and Reiner (23), who analyzed cell pyrolysates. Cellular fatty acid fingerprints of a diverse assortment of organisms, encompassing viruses (4), mycoplasmas (21), bacteria (14), protozoa (8), algae (20), and fungi (17), have now been studied.

Streptococci of the "viridans" group have been subjected to numerical taxonomy $(5,6,13)$ with mixed success. In addition to phenotypically homogeneous species, a residual intractable spectrum of intermediate forms resists attempts to clustering. For the latter ill-defined strains, the term Streptococcus mitis is usually employed. Among the supposedly homogeneous species, Streptococcus mutans has now been shown to be genetically heterogeneous, whereas "Streptococcus milleri" has atypical strains with respect to cariogenicity (10) or to physiological characteristics (3).

Although the term "S. milleri" is widely used by microbiologists in Europe (29), the taxonomic status of such strains is still being determined and the name does not appear on the Approved Lists of Bacterial Names (25).

This study examines the feasibility of applying gas chromatographic fatty acid fingerprints to strains of "S. milleri," S. mitis, and related streptococci.

\section{MATERIALS AND METHODS}

Bacterial strains. A total of 83 strains was examined, including "S. milleri" (28 strains), S. mitis ( 29 strains), $S$. mutans (5 strains), Streptococcus salivarius (6 strains), Streptococcus sanguis (5 strains), and Streptococcus uberis (1 strain), all of the "viridans" group, together with Streptococcus faecalis (6 strains) and Streptococcus pyogenes (3 strains), included for comparative purposes. The strains were from culture collections or were fresh isolates of oral, vaginal, or other origin. The sources of the strains are given in Tables 1, 2, and 3. All of the strains were gram-positive, catalase-negative cocci occurring in chains and capable of growth under aerobic or microaerophilic conditions. Species identifications were made on the basis of the results from a minimum of 20 additional tests (10) supplemented by the test for production of hydrogen peroxide.

Growth and harvesting. Freeze-dried cultures were rechecked for purity and physiological characteristics before growth. Starter cultures, consisting of 1.0$\mathrm{ml}$ samples of brain-heart infusion cultures, were incubated at $37^{\circ} \mathrm{C}$ for $18 \mathrm{~h}$, inoculated into triplicate $100-\mathrm{ml}$ volumes of brain heart infusion, and incubated at $37^{\circ} \mathrm{C}$ for $48 \mathrm{~h}$, in a shaking water bath, without aeration. After growth, cells were harvested by centrifugation at $6,000 \times g$ for $30 \mathrm{~min}$. Before being freezedried, the cells were washed at $4.0^{\circ} \mathrm{C}$ first with $0.1 \mathrm{M}$ double phosphate buffer ( $\mathrm{pH} \mathrm{7.2)}$ and then with distilled water.

Fatty acid extraction. Freeze-dried cells (10 mg) were transesterified in sealed ampoules in triplicate. The extraction procedure and the boron trifluoridemethanol reagent were described previously (15). After extraction, cooled ampoules were opened, and methyl carboxylic esters were twice extracted with heptane and an equal volume of water. Centrifugation resulted in phase separation of the emulsion which formed on shaking. Grease, rubber, and plastic materials were avoided as they introduce artifacts (9). Pooled heptane phases were stored at $-18^{\circ} \mathrm{C}$ and concentrated to $20 \mu \mathrm{l}$ immediately before analysis.

Gas chromatographic analysis. Each triplicate heptane extract was itself analyzed thrice by gas chromatography by injection of $2.0-\mu \mathrm{l}$ samples onto a coiled glass column ( 183 by $4 \mathrm{~mm}$ inside diameter) packed with $10 \%(\mathrm{wt} / \mathrm{wt})$ polyethylene glycol adipate on a diatomite $\mathrm{C}$ support (100 to $120 \mathrm{mesh}$ ). The column was operated isothermally at $190^{\circ} \mathrm{C}$ in a PYE 104 chromatograph with a flame ionization detector operated at $200^{\circ} \mathrm{C}$. The carrier gas was nitrogen, employed 


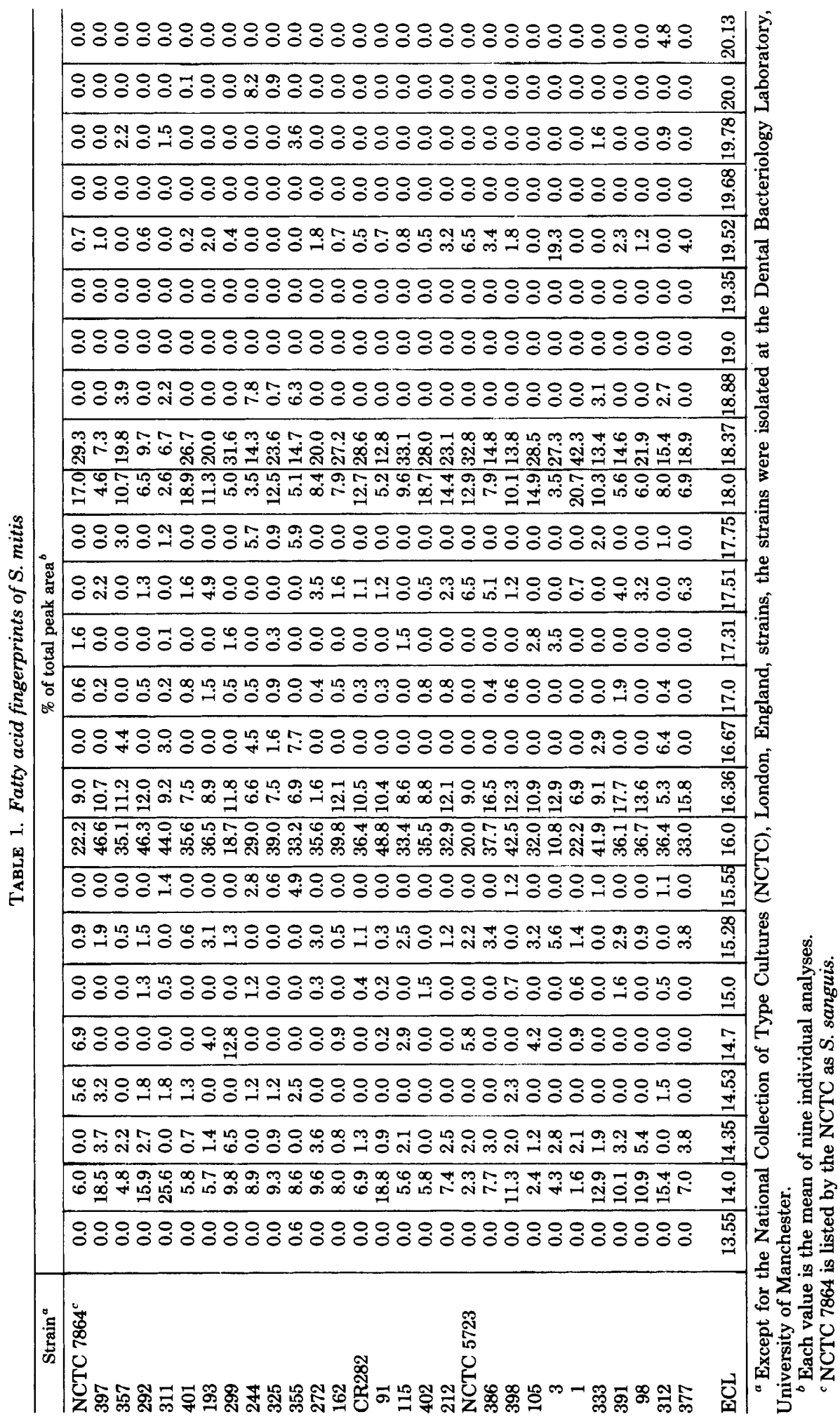




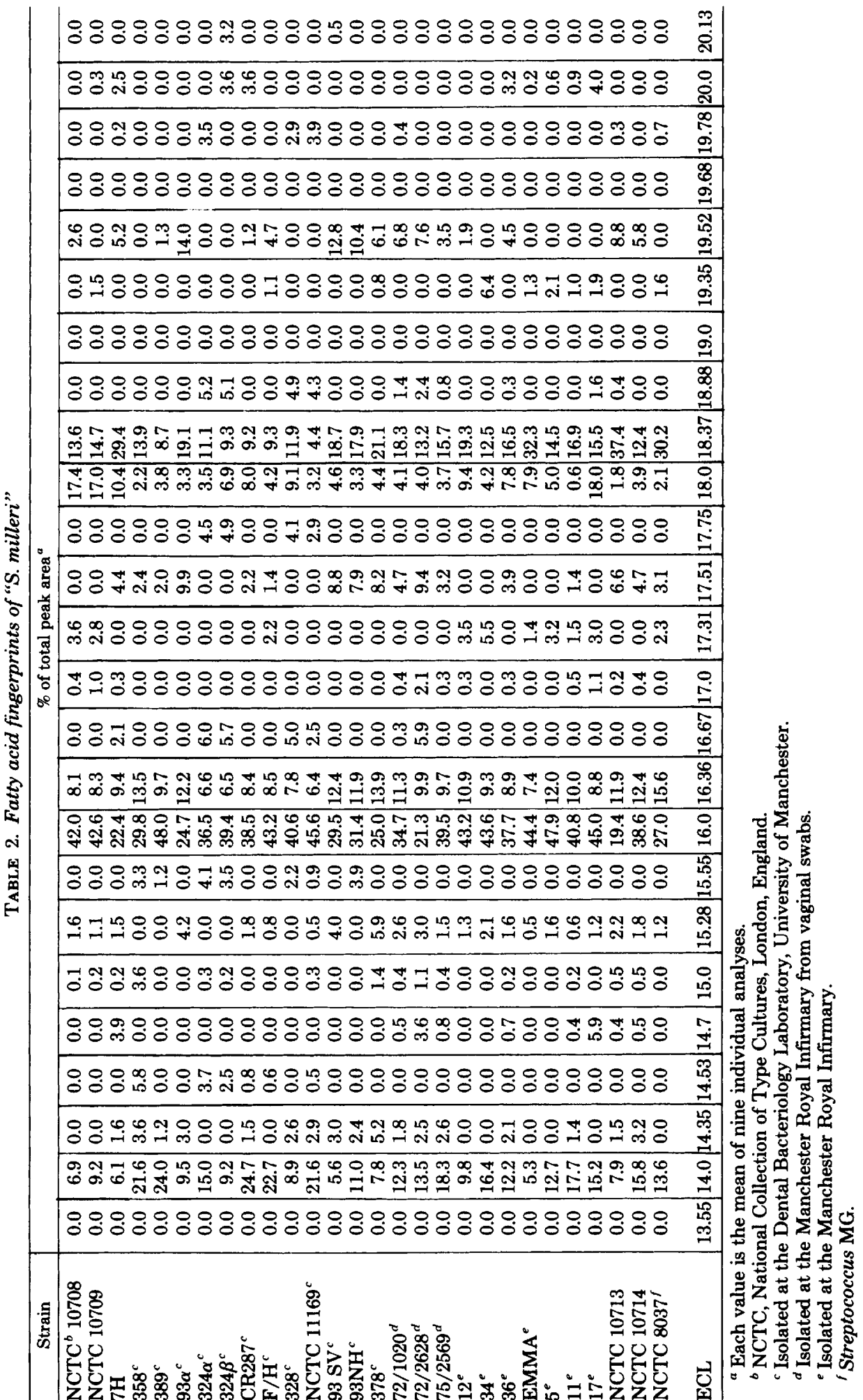




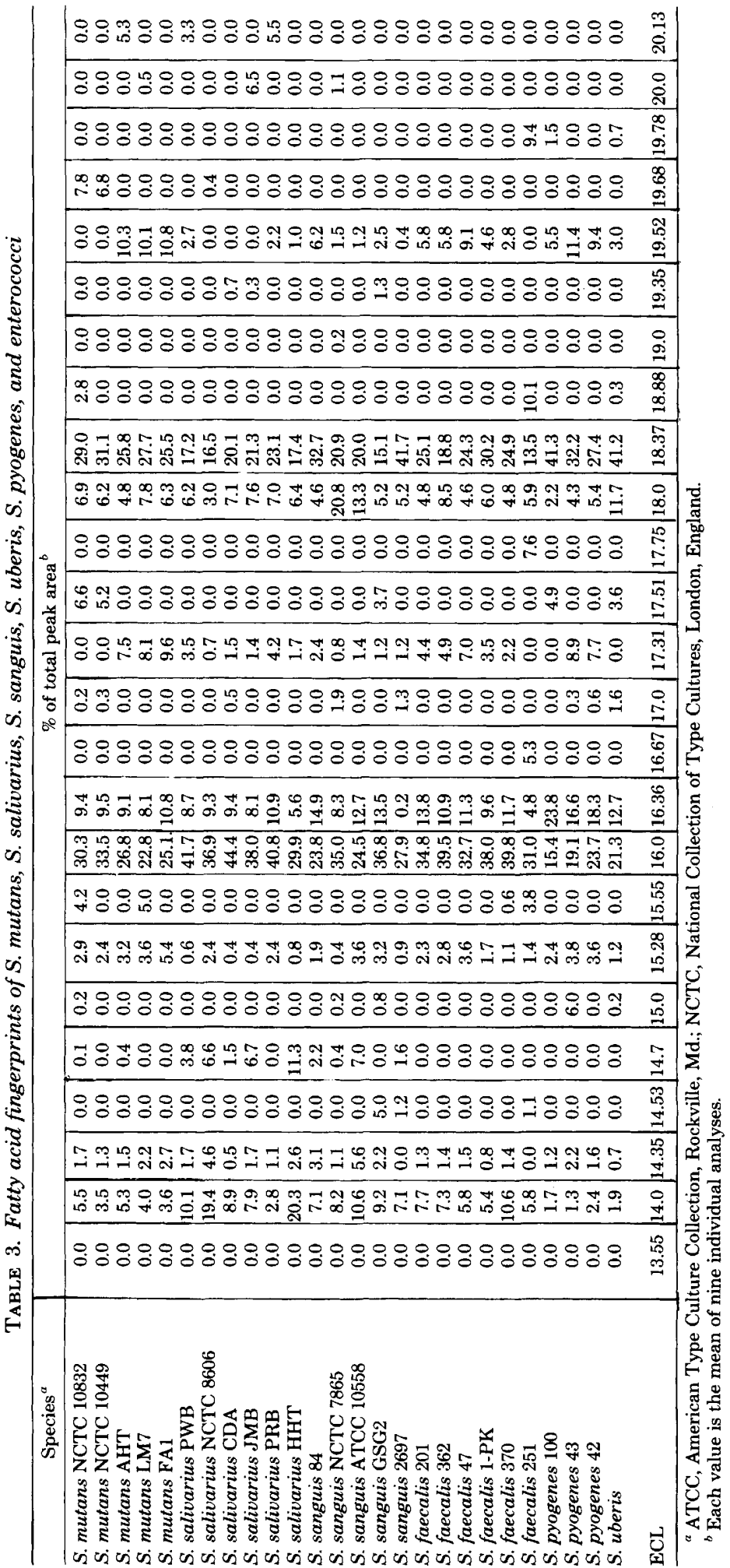


at $40 \mathrm{ml} / \mathrm{min}$. Retention times and individual peak areas were determined by a Spectraphysics computing integrator. An analysis of integrator data (12) provided mean peak areas with standard deviations and mean equivalent chain length (ECL), which enabled tentative peak identifications to be made (22). A few representative strains were selected for further study to confirm the identities of peaks. The methods used have been previously described $(11,15)$, and they included cochromatography with standards, reanalysis on a nonpolar column, separation of enoate classes, bromination, and on-line mass spectrometry. These techniques proved more successful for major peaks than for trace components.

\section{RESULTS}

Mean equivalent chain lengths of esters were computed with sufficient accuracy $( \pm 0.01)$ to permit identification, in different analyses, of peaks due to the same ester. The individual results are tabulated in Tables 1, 2, and 3. Qualitative data for species are listed in Table 4. All of the strains tested had peaks of the following ECL values and tentative identities: 14.00 (tetradecanoate), 16.00 (hexadecanoate), 16.36 (hexadecenoate), 18.00 (octadecanoate), and 18.37 (octadecenoate). The peaks used for computer analysis were those of ECL 13.6 up to 20.2. Results for $S$. mutans are segregated by serovar (Table 3) whereas those for the majority of " $S$. milleri" strains are differentiated by source ( $\mathrm{Ta}$ ble 2). Data from Tables 1, 2, and 3 are collated in Table 4, where results for individual species are expressed as "+," “-," or " \pm ." To compensate for the increased likelihood of an aberrant strain when numbers in a group increase, results were categorized as " + " when $84 \%$ or more of the strains were positive and as "-" when $84 \%$ or more of the strains were negative in any given species.

\section{DISCUSSION}

The finding of tetradecanoate, hexadecanoate, hexadecenoate, octadecanoate, and octadecenoate as major peaks in the cellular fatty acids of the streptococci studied largely agrees with the findings of other workers $(15,18,24,26)$, who generally examined smaller numbers of strains. Eicosenoate was not computed because only peaks of ECL 13.6 up to 20.2 were considered in this study; the deliberate exclusion of peaks having a retention similar to that of eicosenoate avoided consideration of peaks whose massspectral characteristics differ from those of eicosenoate (unpublished data). Although quantitative differences between species will be calculated elsewhere, qualitative differences between species are apparent and valid since all strains were examined under the same condi-

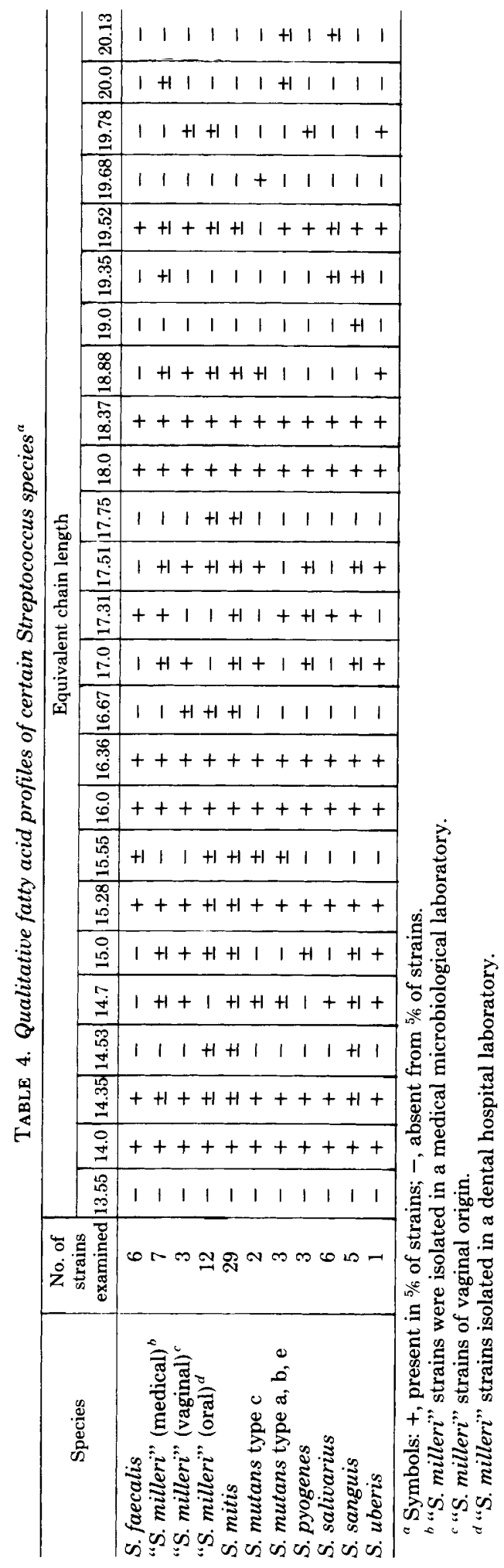


tions, thereby overcoming the experimental variation between studies $(15,18,26)$, which otherwise limits the usefulness of the technique, just as traditional tests also show interlaboratory variation.

In this study, a few strains of $S$. faecalis, $S$. pyogenes, and other species were incorporated as internal references. $S$. mitis has been shown to possess tetradecanoate, hexadecanoate, hexadecenoate, octadecanoate, and octadecenoate as major peaks in a study (18) employing two strains only; in this study, these esters also were the major peaks in the 29 strains examined. Peaks due to other esters were not invariably present or absent, as Table 4 indicates. This heterogeneity with respect to cellular fatty acids mirrors the diverse nature of members of this "catch-all" species as shown by numerical taxonomy (13).

The cellular fatty acid profiles of "S. milleri" shed light on the disparate nature of strains assigned to this species. Three separate groups of strains appear to exist, namely strains of oral origin capable of inducing caries in gnotobiotes (10), strains of vaginal origin, and strains from abscesses and infected wounds, referred to as "medical" strains. Traditional physiological tests do not permit a distinction between the first and third of these groups of strains; however, the fatty acid data, in addition to cariogenicity, are useful in this regard. The vaginal strains can be recognized as distinct from other "S. milleri" strains on physiological grounds.

Too few strains of the other species were examined for firm conclusions to be drawn; however, certain trends were noted. $S$. mutans serovar c appeared to have heptadecanoate, whereas members of other serovars appeared to have heptadecenoate. Heptadecanoate has been shown to be present only under certain growth conditions (15), and even then at not more than $0.2 \%$ of the total peak area for S. mutans NCTC 10832 , the value obtained in the present study. But for electronic integration of peaks and subsequent computer authentication of data, this small peak would have been discarded as being due to an irregular base line. This may account for its seeming absence in other studies (18). The presence of very low amounts of branchedchain acids in certain strains of $S$. mutans corroborates some workers' findings but not others (26). This may be a reflection on the analytical and computer methods employed, the nature of the growth medium, or the esterification method. Traces of these acids have been demonstrated, however, even in cells grown in a synthetic medium (12). S. salivarius appeared to have the same major acids as the preceding species; this finding agrees with data for only five strains reported elsewhere (18). The lack of variable data (Table 4) indicated the homogeneity of the strains tested; $S$. sanguis, on the other hand, showed greater variation in fatty acid content.

The major fatty acids of the above-mentioned species and of $S$. faecalis and $S$. mutans agree, in general, with the findings for Streptococcus lactis (19), S. faecalis $(2,14)$, and S. pyogenes (24). These major acids are quite different from those of some genera of gram-positive cocci (16, 27,28 ). The percentage analyses in this and other studies must be qualified by the knowledge that total recovery of fatty acid, losses due to destruction or evaporation, and molar detector response factors may be unknown. Such limitations do not detract from the benefits accruing from application of gas chromatography to streptococcal classification.

\section{REPRINT REQUESTS}

Address reprint requests to: Dr. D. B. Drucker, Department of Bacteriology and Virology, University of Manchester, Stopford Building, Oxford Road, Manchester M13 9PT, Great Britain.

\section{LITERATURE CITED}

1. Abel, K., H. de Schmertzing, and J. I. Peterson. 1963. Classification of microorganisms by analysis of chemical composition. 1. Feasibility of utilizing gas chromatography. J. Bacteriol. 85:1039-1044.

2. Amstein, C. F., and P. A. Hartman. 1973. Differentiation of some enterococci by gas chromatography. J. Bacteriol. 113:38-41.

3. Ball, L. C., and M. T. P. Parker. 1979. The cultural and biochemical characters of Streptococcus milleri strains isolated from human sources. J. Hyg. Cambridge 82: 63-78.

4. Blough, H. A. 1971. Fatty acid composition of individual phospholipids of influenza virus. J. Gen. Virol. 12:317320.

5. Carlsson, J. 1968. A numerical taxonomic study of human oral streptococci. Odontol. Revy 19:137-160.

6. Colman, G. 1968. The application of computers to the classification of streptococci. J. Gen. Microbiol. 50:149158.

7. Coykendall, A. L. 1974. Four types of Streptococcus mutans based on their genetic, antigenic, and biochemical characteristics. J. Gen. Microbiol. 83:327-338.

8. Dixon, H., and J. Williamson. 1970. The lipid composition of blood and culture forms of Trypanosoma lewisi and Trypanosoma rhodesiense compared with that of their environment. Comp. Biochem. Physiol. 33:111128.

9. Drucker, D. B. 1976. Gas-liquid chromatographic chemotaxonomy, p. 52-125. In J. R. Norris (ed.), Methods in microbiology, vol. 9. Academic Press, Inc., London.

10. Drucker, D. B., and R. M. Green. 1978. The relative cariogenicities of Streptococcus milleri and other viridans group streptococci in gnotobiotic hooded rats. Arch. Oral Biol. 23:183-187.

11. Drucker, D. B., J. Greenman, and T. H. Melville. 1976. Fatty acid profiles of Streptococcus mutans NCTC 10832 grown on synthetic medium with sucrose, fructose or sorbitol. Microbios 16:227-231.

12. Drucker, D. B., C. J. Griffith, and T. H. Melville. 1976. 
Fatty acid fingerprints of some chemostat-grown streptococci with computerized data analysis. Microbios Lett. 1:31-34.

13. Drucker, D. B., and T. H. Melville. 1971. The classification of some oral streptococci of human or rat origin. Arch. Oral Biol. 16:845-853.

14. Drucker, D. B., and I. Owen. 1973. Chemotaxonomic fatty acid fingerprints of bacteria grown with, and without, aeration. Can. J. Microbiol. 19:247-250.

15. Drucker, D. B., and F. J. Veazey. 1977. Fatty acid fingerprints of Streptococcus mutans NCTC 10832 grown at various temperatures. Appl. Environ. Microbiol. 33:221-226.

16. Girard, A. E. 1971. A comparative study of the fatty acids of some micrococci. Can. J. Microbiol. 17:1503-1508.

17. Kish, Z., and R. C. Jack. 1974. Phospholipids of two strains of dermatophyte Arthroderma uncinatum. Lipids 9:264-268.

18. Lambert, M. A., and C. W. Moss. 1976. Cellular fatty acid composition of Streptococcus mutans and related streptococci. J. Dent. Res. 55A:96-102.

19. MacLeod, P., and J. P. Brown. 1963. Fatty acid composition of lipids from Streptococcus cremoris and Streptococcus lactis var. meltigenes. J. Bacteriol. 85: 1056-1060.

20. Matucha, M., L. Žilka, and K. Švihel. 1972. Gas chromatographic analysis of the higher fatty acids of the alga Chlorella vulgaris (pyrenoidosa). J. Chromatogr. 65:371-376.

21. Meyer, D. M., and D. J. Blazevic. 1971. Differentiation of human mycoplasma using gas chromatography. Can.
J. Microbiol. 17:297-300.

22. Miwa, T. K., K. L. Mikolajezak, F. R. Earle, and I. A. Wolff. 1960. Gas chromatographic characterisation of fatty acids. Identification constants for mono- and dicarboxylic methyl esters. Anal. Chem. 32:1739-1742.

23. Reiner, E. 1965. Identification of bacterial strains by pyrolysis gas-liquid chromatography. Nature (London) 206: 1272-1274.

24. Shioiri-Nakano, K., and I. Tadokoro. 1970. Sugar and fatty acid composition of hemolytic Streptococcus, $p$. 383-386. In H. lizuka and T. Hesegawa (ed.), Culture collections of microorganisms. Proceedings of the International Conference on Culture Collections. University Park Press, Baltimore.

25. Skerman, V. B. D., V. McGowan, and P. H. A. Sneath (ed.). 1980. Approved lists of bacterial names. Int. J. Syst. Bacteriol. 30:225-420.

26. Szabo, E. I., B. H. Amdur, and S. S. Socransky. 1978. Lipid composition of Streptococcus mutans. Caries Res. 12:21-27.

27. Uchida, K., and K. Mogi. 1971. Fatty acid spectra of Pediococcis urinae-equi, $P$. homari comparing with other pediococci. An application of high resolution capillary column gas-liquid chromatography for bacterial taxonomy. Agric. Biol. Chem. 35:136-139.

28. Wells, C. L., and C. R. Field. 1976. Long-chain fatty acids of peptococci and peptostreptococci. J. Clin. Microbiol. 4:515-521.

29. Wilson, G. S., and A. A. Miles. 1975. Topley \& Wilson's principles of bacteriology, virology and immunity, 6th ed., vol. 1, p. 714. Edward Arnold, London. 